\title{
Preparation Pilocarpine Hydrochloride Selective Electrodes
}

\author{
Amina M. Abass \\ Department of Chemistry, College of Science, Al-Nahrain University, Al-Jaderia, Baghdad-Iraq. \\ Corresponding Author: aminamohsen75@gmail.com.
}

\begin{abstract}
New eight selective electrodes of pilocarpine hydrochloride deepened on complexes of $(\mathrm{PCH})$-molybdophosphoric acid and $(\mathrm{PCH})$ - phosphotungstate were prepared with varied plasticizers. Electrode with complex (DBPH-MP) was used as an active material, gave linear range from $5.0 \times 10^{-2}$ to $6.0 \times 10^{-5} \mathrm{M}$, and slope was $62.01 \mathrm{mV} /$ decade, with detection limit was $2.0 \times 10^{-5} \mathrm{M}$, lifetime was near to 60 days. Electrode's membrane made with active material (DBP-MP), showed concentration range was $2.1 \times 10^{-3}-6.3 \times 10^{-5} \mathrm{M}$, the slope was near to $52.34 \mathrm{mV} /$ decade. Detection limit was $1.0 \times 10^{-5} \mathrm{M}, 55$ days was the life time of this electrode. The parameters of electrode deepened on (DBPH-PT), concentration range was from $5.0 \times 10^{-2}$ to $6.5 \times 10^{-5} \mathrm{M}$ with slope $50.41 \mathrm{mV} /$ decade, $2.2 \times 10^{-5} \mathrm{M}$ was the detection limit.Life time was determined around to 52 days.

[DOI: 10.22401/JNUS.20.4.03]
\end{abstract}

Keywords: Pilocarpine reactions, Sensors, membrane of PVC.

\section{Introduction}

Chemical name of Pilocarpine hydrochloride $(\mathrm{PCH})$ is $(3 \mathrm{~S}, 4 \mathrm{R})$ Etheyl4-(1methyl-1H-imidazol-5-ylmethyl4,5dihydrofuran-2(3H)-one monohydrochloride, Pilocarpine hydrochloride exist as white crystal or powder, soluble in alcohol and water, practically insoluble in widely nonpolar solvents, $244.72 \mathrm{gm} \mathrm{mol}^{-1}$ has a molecular weight of it. It is used in treatment of glaucoma [1].

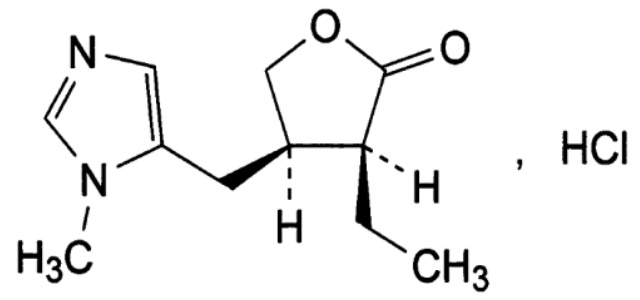

\section{Fig.(1): Structure of pilocarpine hydrochloride.}

Liquid chromatography Generality methods used to limitation of pilocarpine hydrochloride by using column: $\beta$ - cyclodextrin [2], and in biological fluids [3]. First derivative were evaluated for pilocarpine hydrochloride by UV spectrophotometry at $\lambda_{1}=222 \mathrm{~nm}$ and $\lambda_{2}=307 \mathrm{~nm}$ [4]. Measurements of mercuric content of pilocarpine complex by atomic absorption spectroscopic (AAS), the method was give recovery around (99.15 \pm 0.79$)$ [5]. Spectrum of $\mathrm{PCH}, \mathrm{C}_{11} \mathrm{H}_{17} \mathrm{~N}_{2} \mathrm{O}_{2} \mathrm{Cl}$ at $300 \mathrm{~K}$ founded by (FT)-Raman spectrum and (FT-IR) spectrum [6]. For neutralization have need of a minimum quantity of alkali with $\mathrm{PH}=5$ was used to constraction by used $93 \%$ of the unique pilocarpine [7]. Pilocarpine salt such as poly (methyl methacrylate) and nitrate, hydrochloride, onto) was studied as a sorption behavior [8]. Colorimetric method was optimized to determination of pilocarpine hydrochloride by control of time, concentration and $\mathrm{PH}, \mathrm{r}=0.9800$ with intercept 0.07 with slope $=0.51[9]$. Electrodes of pilocarpine deepened on $\mathrm{PCH}$-tetrakis (4-chloro phenyl) borate and $\mathrm{PCH}$-tetrakis [3,5 bis(triflouromethyl)-phenyl borate construction without internal reference solution, concentration rang was near to $3.0 \times 10^{-5}$ and $6.0 \times 10^{-5}$ to $10^{-1} \mathrm{M}$, repectively [10]. Nernstian response for $4 \times 10^{-5}-10^{-1} \mathrm{M}$ with $\mathrm{PH}$ about 4.0- 6.5 with good selectivity for $\mathrm{PCH}$ by using PVC matrix with (pilocarpine-reineckatc)ion pair complex, as an material electroactive [11].

\subsection{Chemicals Details}

High molecular weight poly(vinyl chloride)(PVC), Breon S110/10 B.P chemical U.K.Ltd, Tetrahydrofuran (THF) was from (BDH), Pilocarpine hydrochloride from State Company of Medical Appliances and Drug Industries (Samara IRAQ-SDI). Salagen, film coated (tablet, 5mg) product of 
Chemical Industries Development Giza. phosphotungstate (PT), molybdophosphoric acid (MP), o-nitro phenyl octyl ether (o-NPOE), di-n-butyl phthalate (DBPH), tri-butylphosphate (TBP), di-n-butyl phosphate (DBP), were achieved from Fluka.PH effect was governed through using $0.1 \mathrm{M}$ of sodium hydroxide and hydrochloric acid. Nearly analytical class chemicals and distilled water were used in experiments.

\subsection{Standard Drug Solutions}

Standard solutions $1 \times 10^{-6}$ to $1 \times 10^{-1} \mathrm{M}$ of Pilocarpine hydrochloride $(\mathrm{PCH})$ were equipped by successive dilutions from standard solution $\left(1 \times 10^{-1} \mathrm{M}\right)$ with spending distilled water.

\subsection{Preparation Of ion-pair}

Prepared Pilocarpine hydrochlorideMolybdophosphoric acid (PCH- MP) and Pilocarpine hydrochloride - phosphotungstate (PCH-PT) ion pairs via mixing $50 \mathrm{ml}$ of $0.01 \mathrm{M}$ from drug $(\mathrm{PCH})$ with $50 \mathrm{ml}$ of $0.01 \mathrm{M}$ from Molybdophosphoric acid and50 $\mathrm{ml}$ of $0.01 \mathrm{M}$ from $\operatorname{drug}(\mathrm{PCH})$ with $50 \mathrm{ml}$ of phosphotungstate, however stirring. Filtered the product precipitate and washed using water, at room temperature became dry.

\subsection{Preparation of membrane}

PVC membrane was equipped with mixed $0.04 \mathrm{~g}$ of (PCH-MP) with $0.36 \mathrm{gm}$ of plasticizers:(o-NPOE,DBP,TBP,DBPH). 0.17 $\mathrm{g}$ of PVC was mixed with 6-7 $\mathrm{ml}$ of THF, stirring until was be sticky solution. Then two solutions were mixed with stirring, and poured into a glass ring of ( 5 diameter) protected and left attitude over nighttime to let sublimation of the THF at room temperature [12]. From this membrane could prepare about 10 electrodes. Tube of glass was filled $3 / 4$ stock solution $0.1 \mathrm{M}$ of drug $\mathrm{M}$ [13].

\subsection{Equipment}

1. Microprocessor, $\mathrm{pH} / \mathrm{mV} / \mathrm{C}$ Meter, $\mathrm{pH} 211$, HANA, Made in Romania.

2. Gallen Kamp (USA) as Calomel Reference Electrode.

3. Electrode of PH, H11131, HANA Instruments.
4. Conductance measurement founded by used conductivity meter type: Benchtop Conductivity Meter, TRANS Instruments, BC 302.

\section{Results and Discussion}

Results of electrode parameters acquired from the calibration graphs, are recorded in Table (1), and a typical calibration curve for the pilocarpine electrodes is shown in Chart.1, 2 for membrane $\mathrm{E}_{1}$. The constancy of the eight electrodes was checked always by using pilocarpine hydrochloride at concentration $1.00 \times 10^{-3} \mathrm{M}$ of solution and assessed daily. 
Table (1)

Pilocarpine hydrochloride electrodes responses.

\begin{tabular}{|c|c|c|c|c|c|c|}
\hline Elec. No. & Electrode membrane & $\begin{array}{c}\text { Slope } \\
\text { (mV/decade) }\end{array}$ & $\begin{array}{c}\text { concentration } \\
\operatorname{range}(M)\end{array}$ & $\begin{array}{c}\text { Detection } \\
\operatorname{limit}(M)\end{array}$ & $\begin{array}{c}\text { Resp. } \\
\text { time } \\
(\mathrm{sec})\end{array}$ & $\begin{array}{l}\text { Life time } \\
\text { (day) }\end{array}$ \\
\hline $\mathbf{E}_{1}$ & PCH+MP+DBPH & 62.01 & $5.0 \times 10^{-2}-6.0 \times 10^{-5}$ & $2.0 \times 10^{-5}$ & 8 & 60 \\
\hline $\mathbf{E}_{2}$ & PCH+MP+DBP & 52.34 & $2.1 \times 10^{-3}-6.3 \times 10^{-5}$ & $1.0 \times 10^{-5}$ & 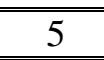 & 55 \\
\hline $\mathbf{E}_{3}$ & PCH+MP+TBP & 47.44 & $6.2 \times 10^{-3}-1.0 \times 10^{-5}$ & $5.0 \times 10^{-2}$ & 12 & 33 \\
\hline$\overline{\mathbf{E}_{4}}$ & $\overline{\mathrm{PCH}+\mathrm{MP+NPOE}}$ & 11.58 & $1.2 \times 10^{-1}-5.5 \times 10^{-3}$ & $1.0 \times 10^{-1}$ & 7 & 19 \\
\hline $\mathbf{E}_{5}$ & PCH+PT+DBPH & 50.41 & $5.0 \times 10^{-2}-6.5 \times 10^{-5}$ & $2.2 \times 10^{-5}$ & 6 & 52 \\
\hline $\mathbf{E}_{6}$ & PCH+PT+DBP & 37.30 & $6.5 \times 10^{-1}-6.6 \times 10^{-3}$ & $3.3 \times 10^{-1}$ & 6 & 18 \\
\hline$\overline{\mathbf{E}_{7}}$ & PCH+PT+TBP & 11.49 & $1.0 \times 10^{-4}-1.0 \times 10^{-6}$ & $1.0 \times 10^{-4}$ & $\overline{5}$ & 12 \\
\hline$\overline{E_{8}}$ & "PCH+PT+NPOE & $\overline{70.01}$ & $5.6 \times 10^{-2}-9.7 \times 10^{-4}$ & $3.3 \times 10^{-2}$ & $\overline{3}$ & 7 \\
\hline
\end{tabular}

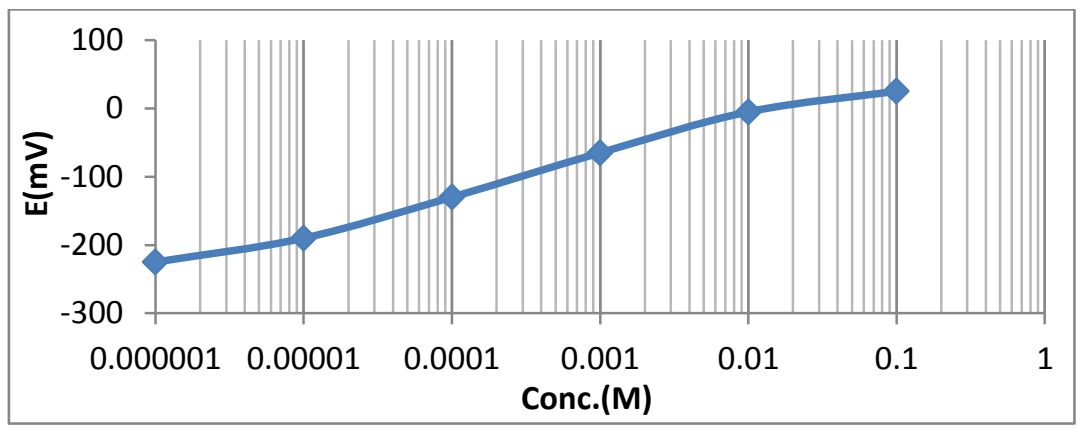

Chart (1): Response of electrode $E_{1}$.

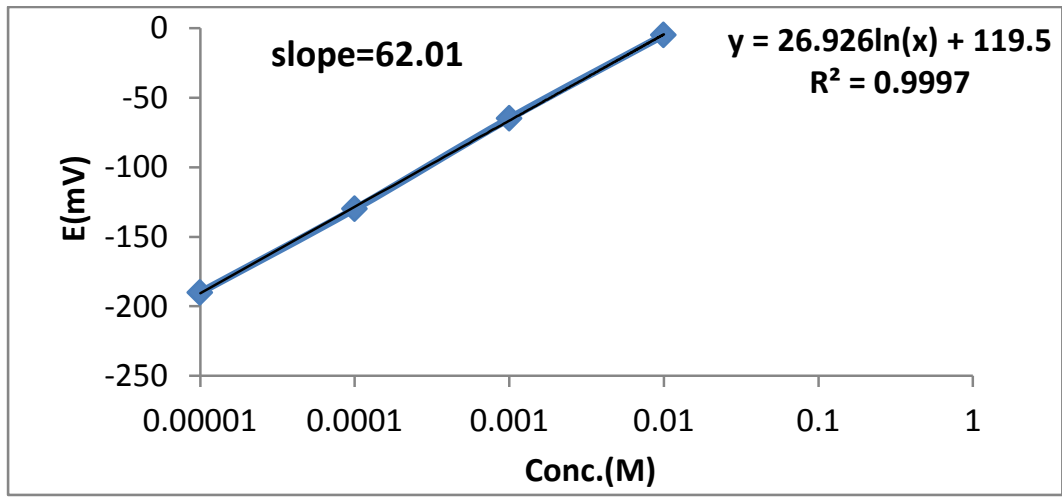

Chart (2): Calibration graph of electrode $E_{1 .}$.

Potential reply of the recommended electrode $E_{1}$ at changing concentrations of $\mathrm{PCH}$ donated a slope of $62.01 \mathrm{mV} /$ decade, detection limit of $2.0 \times 10^{-5} \mathrm{M}$, lifetime of close to 60 days. Conversely, membrane $\mathrm{E}_{2}, \mathrm{E}_{5}$ were gave away slopes 52.34, $50.41 \mathrm{mV} /$ decade, respectively, and lifetime of around 55,52 day, respectively. Membrane $\mathrm{E}_{8}$ donated a slope near to $70.01 \mathrm{mV} /$ decade, 7 days was the lifetime this could be ascribed to the opposition of NPOE with the complex (PCH-MP) beginning outflow of the complex to the external solution from the membrane [14].

\subsection{Effect of $P H$}

$\mathrm{PH}$ effect of pilocarpine hydrochloride solutions for concentration $1 \times 10^{-3} \mathrm{M}$ on the response of the electrodes potential was investigated. The operational $\mathrm{PH}$ ranges are recorded in Table (2).

\section{Table (2)}

Range of $\mathrm{PH}$ for pilocarpine electrodes.

\begin{tabular}{|c||c||c||}
\hline Electrode No. & Plasticizers & pH range \\
\hline $\mathbf{E}_{\mathbf{1}}$ & DBPH+MP & $3.6-7.8$ \\
\hline $\mathbf{E}_{\mathbf{2}}$ & DBP+MP & $2.3-7.8$ \\
\hline $\mathbf{E}_{\mathbf{5}}$ & DBPH+PT & $3.0-7.8$ \\
\hline
\end{tabular}




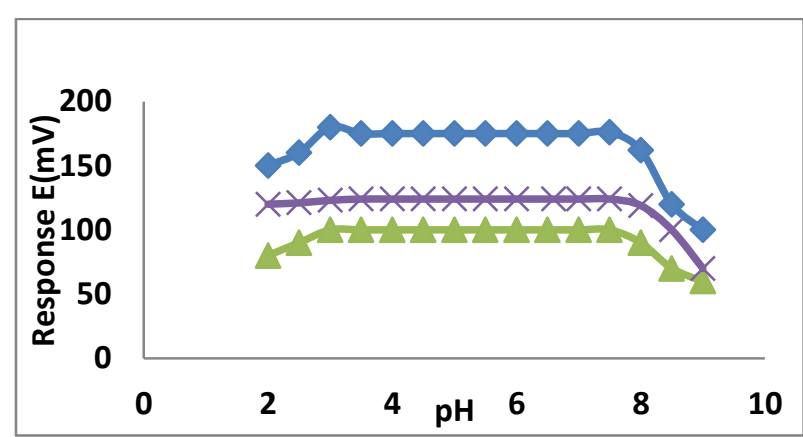

Chart (3): Response of pH effect for (PCH) electrodes at concentration $10^{-3} \mathrm{M}$ of pilocarpine hydrochloride solution, $E_{1}, \times E_{2}, \Delta E_{5}$.

Characteristic plot for effect of $\mathrm{pH}$ on pilocarpine electrodes was presented in Chart.3. PH range of $E_{1}$ was about 3.6-7.8 and $\mathrm{PH}$ range for $\mathrm{E}_{2}$ was $2.3-7.8, \mathrm{PH}$ for $\mathrm{E}_{5}$ near to $3.0-7.8$; therefore, the suggested electrodes could be used to evaluating a wide series of pilocarpine concentrations. On the other hand, exterior this series the responses of electrodes change. Explicitly at $\mathrm{pH}$ values upper than 7.8 might be justified by removing the positive charge on the drug molecules [15]. At $\mathrm{pH}$ lesser than 2.0 (high acidity) response's electrode was amplified sporadically; because the electrodes reply became to activities of $\mathrm{H}^{+}$ only.

\subsection{Effect Of temperature}

The temperature effect for electrodes with concentration from $10^{-6}$ to $10^{-2} \mathrm{M}$ of pilocarpine solutions were studied in $25,30,35,40{ }^{\circ} \mathrm{C}$. At dissimilar temperature were donated diverse of slope is stated in Table (3).

Table (3)

Different temperatures effect of pilocarpine electrodes.

\begin{tabular}{|c||c|c||}
\hline $\begin{array}{c}\text { No. of } \\
\text { Electrode }\end{array}$ & $\begin{array}{c}\text { Temperature } \\
{ }_{\mathbf{0}}^{\mathbf{C}}\end{array}$ & $\begin{array}{c}\text { Slope } \\
\text { (mV/decade) }\end{array}$ \\
\hline \multirow{4}{*}{$\mathbf{E}_{\mathbf{1}}$} & 25 & 62.01 \\
& 30 & 72.35 \\
& 35 & 81.23 \\
& 40 & 97.50 \\
\hline \hline & 25 & 52.34 \\
$\mathbf{E}_{\mathbf{2}}$ & 30 & 65.10 \\
& 35 & 77.60 \\
& 40 & 100.43 \\
\hline \hline & 25 & 50.41 \\
$\mathbf{E}_{\mathbf{5}}$ & 30 & 65.90 \\
& 35 & 75.12 \\
& 40 & 92.78 \\
\hline
\end{tabular}

As of Table (3), it is apparent that a suitable Nernstian reply at temperatures $25-30^{\circ} \mathrm{C}$, electrodes, slope were leap to a very rising value at $40^{\circ} \mathrm{C} \quad(97.50,100.43 .92 .78) \mathrm{m}$ Vdecade $^{-1}$, respectively that might be quality to disintegration of ion pair.

\subsection{Selectivity}

Separate solution method were used to calculated the selectivity coefficient of the electrode from the reshuffled NickolskyEisenman equation [16]:

Log. $\mathrm{K}_{\mathrm{A}, \mathrm{B}}^{\mathrm{pot}}=[(\mathrm{EB}-\mathrm{EA}) \mathrm{z} \mathrm{A} F / 2.303 \mathrm{RT}]+$ $(1-\mathrm{z} A / \mathrm{z} B) \log$ a $\mathrm{A}$.

The stimulus of some inorganic cations interfering for example $\mathrm{Fe}^{+3}, \mathrm{Al}^{+3}, \mathrm{Mg}^{+2}, \mathrm{Zn}^{+2}$, $\mathrm{Na}^{+1}, \mathrm{~K}^{+1}$ on the response of electrode as well considered Selectivity for electrodes $\mathrm{E}_{1}, \mathrm{E}_{2}$ and $E_{5}$, was estimated for concentration $10^{-3} \mathrm{M}$ with the separation method. The value of the selectivity coefficient for $E_{1}, E_{2}$ and $E_{5}$ electrodes are scheduled in Table (4) and selectivity of $(\mathrm{PCH}+\mathrm{MP}+\mathrm{DBPH})$ electrode for interfering $\mathrm{K}^{+1}$ by separation method was shown in Chart.4. 
Table (4)

Separate solution method $\left(1 \times 10^{-3} \mathrm{M}\right.$ of $\mathrm{PCH}$ and the interference $)$ for determination Selectivity coefficient.

\begin{tabular}{|c|c|c|c|}
\hline Interfering Ion & $\begin{array}{c}\mathrm{K}_{\mathrm{A}, \mathrm{B}}^{\mathrm{POT}} \text { for electrode } \\
\mathrm{E}_{1}\end{array}$ & $\begin{array}{c}\mathrm{K}_{\mathrm{A}, \mathrm{B}}^{\mathrm{POT}} \text { for electrode } \\
\mathrm{E}_{2}\end{array}$ & $\begin{array}{c}\mathrm{K}_{\mathrm{A}, \mathrm{B}}^{\mathrm{POT}} \text { for electrode } \\
\mathrm{E}_{5}\end{array}$ \\
\hline $\mathrm{Na}^{+1}$ & $8.076 \times 10^{-3}$ & 0.656 & 1.993 \\
\hline $\mathrm{K}^{+1}$ & $6.347 \times 10^{-3}$ & 0.745 & 1.606 \\
\hline $\mathrm{Mg}^{+2}$ & $1.852 \times 10^{-2}$ & 0.131 & 0.193 \\
\hline $\mathrm{Zn}^{+2}$ & $5.405 \times 10^{-5}$ & 0.106 & 0.229 \\
\hline $\mathrm{Fe}^{+3}$ & $1.175 \times 10^{-5}$ & 0.013 & 0.150 \\
\hline $\mathrm{Al}^{+3}$ & $1.084 \times 10^{-5}$ & $9.588 \times 10^{-3}$ & 0.279 \\
\hline
\end{tabular}

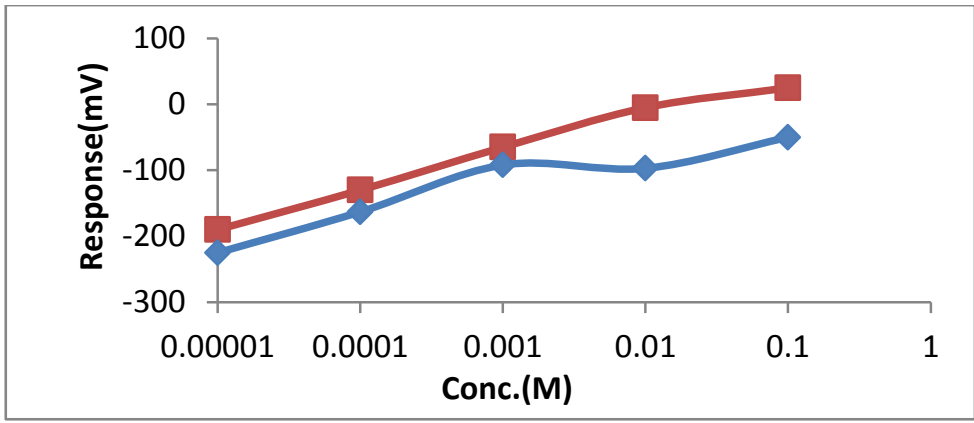

Chart (4): Interfering $\mathrm{K}^{+1}$ by separation method for $(\mathrm{PCH}+\mathrm{MP}+\mathrm{DBPH})$ membrane, - -pilocarpine hydrochloride solution, ${ }^{--}$solution of $K^{+1}$.

The selectivity coefficient were very small less than $(0.1)$ for electrode $E_{1}$ and for ions $\mathrm{Al}^{3+}, \mathrm{Fe}^{+3}$ of electrode $\mathrm{E}_{2}$ with high selectivity coefficients for electrode $E_{5}$, the reason that selectivity of the ions-selective measuring device not only rely on the quality of ion exchanger, but as well meaningfully on the paste conformation, the nature of plasticizers and any spices expended, variances in mobility, ionic size, and porousness.

\subsection{Analytical Applications}

Conductometric and Titration methods to determination of $\mathrm{PCH}$

A concentration of $\mathrm{PCH}$ prepared with transmitted to a beaker then dipped conductivity cell. Then added $10^{-3} \mathrm{M}$ of MP and measured succeeding conductance. After each addition the evaluation was correct for thinning equation of conductivity method had a straight meaning of dilution [17].

$$
\Omega \operatorname{corr}=\Omega \mathrm{abs}[\mathrm{V} 1+\mathrm{V} 2 / \mathrm{V} 1]
$$

$\Omega$ is conductivity of electrolytic, $\mathrm{V} 1=$ first volume, $\mathrm{V} 2=$ volume of the material corrected $=$ corr. and observed $=$ obs
A chart of revised conductivity opposed to volume of the supplemented titrant was formed. In quantitative conductometric this manner was used successfully showed in Chart (5), and titration method was used to determined pilocarpine hydrochloride by made titration between $1 \times 10^{-3} \mathrm{M}$ pilocarpine hydrochloride solution against $1 \times 10^{-3} \mathrm{M}$ of molybdophosphoric acid as a titrant shown in Chart.(6).

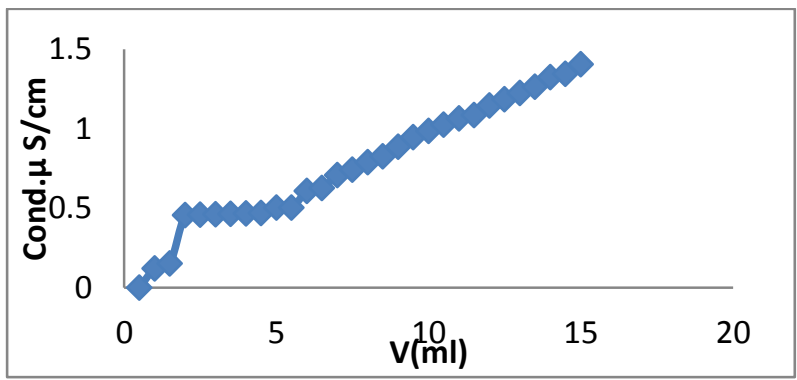

Chart (5): Conductivity measurements for $(\mathrm{PCH}+\mathrm{MP}+\mathrm{DBPH})$ electrode. 


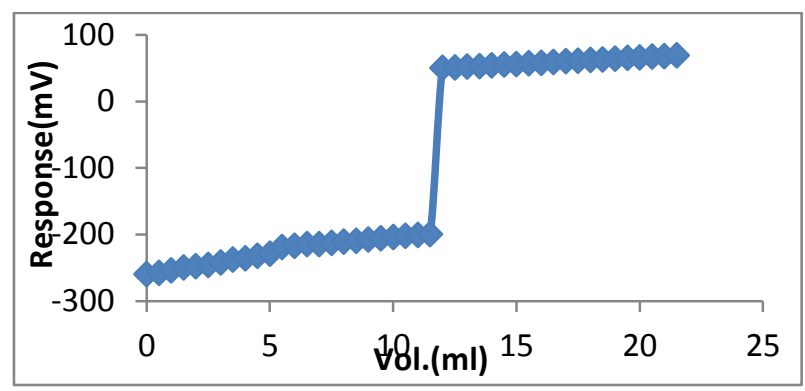

Chart (6): Titration curve for sample $\left(1 \times 10^{-3} \mathrm{M}\right) \mathrm{PCH}$ with $\left(1 \times 10^{-3} \mathrm{M}\right) \mathrm{MP}$ standard by electrode $E 1$.

Upshots of the quantitative magnitudes for $\mathrm{PCH}$ solutions with relative error, relative standard deviations and recovery are recorded in Table (5) and Table (6).

Table (5)

Sample analysis using Conductometric and Titrtion methods for Pilocarpine hydrochloride solutions.

\begin{tabular}{|c|c|c|c|c|c|}
\hline Type of Electrode & Type of Method & $\begin{array}{c}\text { Concentration of } \\
\text { Pilocarpine hydrochloride }\end{array}$ & RSD\% & Er\% & $\operatorname{Re} \%$ \\
\hline \multirow{2}{*}{$\begin{array}{c}\text { PCH+MP+DBPH } \\
\left(\mathrm{E}_{1}\right)\end{array}$} & Conductometric & $1.00 \times 10^{-3}$ & 4.76 & -1.23 & 98.77 \\
\hline & Titration & $1.00 \times 10^{-3}$ & 0.96 & 2.06 & 102.06 \\
\hline \multirow{2}{*}{$\begin{array}{c}\text { PCH+PT+DBPH } \\
\left(\mathbf{E}_{5}\right)\end{array}$} & Conductometric & $1.00 \times 10^{-3}$ & 7.57 & -3.04 & 96.96 \\
\hline & Titration & $1.00 \times 10^{-3}$ & 1.13 & 0.70 & $\overline{100.7}$ \\
\hline
\end{tabular}

From statistical analysis of the piloarpine electrodes, was used for analysis of $\mathrm{PCH}$ in pharmaceutical formulations, RSD\% were 4.76 and 7.57, respectively with Er\% equal to -1.23 and -3.04 , respectively , and $\mathrm{Re} \%$ were $98.77,96.96$, respectively for conductometric method. Although for titration method RSD\% were 0.96 and 1.13 with $\mathrm{Er} \%$ equal to2.06, 0.70 . $\mathrm{Re} \%$ were 102.06 and 100.7 .

Table (6)

Sample analysis using Conductometric and Titration methods for tablets Salagen solutions.

\begin{tabular}{|c|c|c|c|c|c|}
\hline Type of Electrode & Type of Method & $\begin{array}{c}\text { Concentration } \\
\text { of Salagen }\end{array}$ & RSD \% & Er\% & $\operatorname{Re} \%$ \\
\hline \multirow{2}{*}{$\begin{array}{c}\mathrm{PCH}+\mathrm{MP}+\mathrm{DBPH} \\
\left(\mathrm{E}_{1}\right)\end{array}$} & Conductometric & $1.00 \times 10^{-3}$ & 0.06 & 1.00 & 101.00 \\
\hline & Titration & $1.00 \times 10^{-3}$ & 1.00 & -0.64 & 999.36 \\
\hline \multirow{2}{*}{$\begin{array}{c}\mathrm{PCH}+\mathrm{PT}+\mathrm{DBPH} \\
\left(\mathrm{E}_{5}\right)\end{array}$} & Conductometric & $1.00 \times 10^{-3}$ & 5.40 & -5.41 & 94.59 \\
\hline & Titration & $1.00 \times 10^{-3}$ & 1.29 & -0.66 & 99.34 \\
\hline
\end{tabular}

$* n=3$.

Conductometric method for Salagen tablets, RSD\% were 0.06 and 5.40, respectively, with Er\% equal to $1.00,-5.41$ respectively. $\mathrm{Re} \%$ were about 101.00 and 94.59 , respectively, and by titration method RSD\% were $1.00,1.29$, respectively. Er\% were -0.64 and -0.66 , respectively, with $\mathrm{Re} \%$ around 99.36 and 99.34, respectively. From these results could be analysis drugs by used potentiometric techniques. 


\section{References}

[1] "British pharmacopeia on CD-ROM", version 4, copyright by Crown Ltd., London, 84, 2007.

[2] Sternitzke K., Fan T., Dunn D., "Highperformance liquid chromatographic determination of pilocarpine hydrochloride and its degradation products using a $\beta$-cyclodextrin column Original Research Article", Journal of Chromatography A, 589, (1-2), 159-164, 1992.

[3] Aromdee Ch., Fawcett J., Liedger R., "Sensitive high-performance liquid chromatographic assay for pilocarpine in biological fluids using florescence derivatisation Original Research Article", Journal of Chromatography B:Biomedical epimer Sciences and Applications, 677, (2), 313-318,1996.

[4] Satuf M., Robles J., Goicoechea H., Olivieri A., "Simultaneous determination of Timolol Maleate and Pilocarpine Hydrochloride in Ophthalmic solutions by first derivative UV spectrophotometry and PLS-1Multivariate Calibration", Analytical Letters , 32,(10), 2019-2033,1999.

[5] Ayad M., Khayyal S., Farag N., "Indirect determination of pilocarpine by atomic absorption spectrometry", Microchemical Journal, 33, (3), 371-375, 1986.

[6] Bento R., Freire P., Texeira A., Silva J., Lima J., deOliveira M., Andrade-Neto M., Omero N., Pontes F., "Vibrational spectra of pilocarpine hydrochloride crystals", Brazilian Journal of Physics, 39,1, 2009.

[7] Gibb I., Tuckeman M., "Formulation of a stable pilocarpine hydrochloride solution", Journal of Pharmaceutical Sciences, 63, (2), 276-280, 1974.

[8] Harmia T., Speiser P., Kreuter J., "Optimazation of pilocarpine loading onto nanoparticles by sorption procedures", International Journal of Pharmacutics, 33, (1-3), 45-54, 1986.

[9] Gibb I., Tuckeman M., "Optical ferric hydroxamate method for determination of infact pilocarpine", Journal of apharmaceutical Sciences, 59, (3), 375-396, 1970.

[10] Alcada N., Lima J.,Conceicao M., Montenegro B., "Application of poly(vinyl chloride) pilocarpine membrane electrodes in ophthalmic products", Analyst, 119, 2327-2330, 1994.

[11] Elnemma E., "New poly (vinyl chloride) Matrix Membrane Electrode for Manual and Flow Iniection Determination of Pilocarpine in Some Pharmaceutical Preparations", Analytical Letters, 27(10), 1863-1874, 1994.

[12] Al-Atass A., "Novel PVC Membrae Selective Electrode For the Determintion of Clozpine in Pharmaceutical Preparations", International Journal Electrochemical Science, 4, 9-19, 2009.

[13] Al-Saidi K., Ahmed Z., "Construction of Promethazine Hydrochloride Selective Electrodes in A PVC Matrix Membrane", Journal of Al-Nahrain University, 14, (4), 11-17, 2011.

[14] Nassory N., Maki S., Ali M., "Preparation and Characterization of an Atenolol Selective Electrode Based on a PVC Matrix Membrane", Turk J Chem, 31, 75-82, 2007.

[15] Al-Tamimi S., Al-Mohaimeed A., AlArfaj N., Aly F., "Ion Selective Electrodes for Determination of Cefditoren pivoxil in Pharmaceutical Formulations \& Biological Fluids", International Journal of Electrochemical Science, 8, 3988-4001, 2013.

[16] El-Kosasy A., Abedl-Aziz M., Magdy N., El-Zahar N., "Comparative Study of Different Potentiometric Ion-Selective Electrodes for Determination of Certain Polyionic Drugs", International of Electrochemical Science, 11, 3738-3754, 2016.

[17] Ammar R., "A New Ritodrine Selective Electrode and its Pharmaceutical Application", E- Journal of Chemistry, 7, (1), 103-110, 2010. 